\title{
La noción de territorio: retrospectiva, de Santa María del Puerto del Príncipe a Camagüey
}

\begin{abstract}
Mabel Teresa Chaos Yeras ${ }^{1}$
Resumen: El artículo resume aspectos relativos al proceso de formación y desarrollo de las ciudades y la incidencia en ello de las características históricas y geográficas. Atiende de manera particular la ciudad de Santa María del Puerto del Príncipe, actualmente Camagüey, para sustentar que la ciudad es mucho más que un lugar en el plano. Se abordan elementos contenidos en la tesis doctoral de la autora referidos al medio geográfico, los factores socio-urbanísticos y las relaciones entre centro y periferia, con especial mención al papel de las haciendas en el desarrollo de la arquitectura urbana. A través de una retrospectiva en la que subyace la noción de territorio se abordan los problemas actuales a los que se enfrentan las ciudades y la relación entre el medio físico y el desarrollo humano personal. Se destaca la necesidad de acciones de conservación y de la concertación de políticas públicas centradas en el hombre como recurso fundamental de preservación patrimonial.

Palabras-clave: Territorio; espacio físico-social; preservación patrimonial.
\end{abstract}

\section{A noção de território: retrospectiva, de Santa María del Puerto del Príncipe para Camagüey}

Resumo: $O$ artigo resume aspectos relacionados ao processo de formação e desenvolvimento das cidades e a incidência das características históricas e geográficas. Atende de um modo particular a cidade de Santa María del Puerto del Príncipe, atual Camagüey, para sustentar que a cidade é muito mais que um lugar em seu plano urbano. Os elementos contidos na tese de doutorado da autora sobre o ambiente geográfico, os fatores sócio-urbanísticos e as relações entre o centro e a periferia são abordados, com particular referência ao papel das haciendas no desenvolvimento da arquitetura urbana. Uma retrospectiva subjacente à noção de território aborda os problemas atuais enfrentados pelas cidades e a relação entre ambiente físico e desenvolvimento humano pessoal. Destaca-se a necessidade de ações de conservação e acordo de políticas públicas centradas no homem como recurso fundamental para a preservação patrimonial.

Palavras-chave: Território; espaço físico-social; preservação patrimonial.

\section{The notion of territory: retrospective, from Santa María del Puerto del Príncipe to Camagüey}

\begin{abstract}
The article summarizes aspects related to the formation process and development of cities and the impact of the historical and geographical characteristics. It serves in a particular way the city of Santa María del Puerto del Príncipe, currently Camagüey, to support that the city is much more than a place in the plane. Elements contained in the author's doctoral thesis are addressed referring to the geographical medium, socio-urban factors and relationships between center and periphery, with special mention to the role of haciendas in the development of urban architecture. Through a retrospective in the underlying notion of territory, current problems that cities face and the relationship between the physical environment and the personal human development are addressed. The need for actions of preservation and the coordination of public policies focused on the man as a fundamental resource for heritage preservation is highlighted.
\end{abstract}

Keywords: territory, physical-social space, heritage preservation.

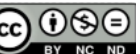

DOI: https://doi.org/10.26512/patryter.v2i4.25004

Como citar este artigo: Chaos, M. T. (2019). La noción de territorio: retrospectiva, de Santa María del Puerto del Príncipe a Camagüey. PatryTer-Revista Latinoamericana e Caribenha de Geografia e Humanidades, 2 (4), pp. 3950. DOI: https://doi.org/10.26512/patryter.v2i4.25004

Recebido: 15 de junho, 2019. Aceite: 27 de agosto, 2019. Publicado: 01 de outubro, 2019.

${ }^{1}$ Doctora por la Universidad de Sevilla, España (2005), título homologado a Doctora en Ciencias Técnicas en Cuba y Profesora Titular de la Universidad de Camagüey, Cuba.

ORCID: https://orcid.org/0000-0002-5138-6949. Email: mabel.yeras@,reduc.edu.cu. 


\section{Introducción}

Las investigaciones realizadas hasta la fecha, sobre la evolución histórica de las ciudades, han estado marcadas por las diferentes corrientes de pensamiento y han evolucionado hasta la actualidad donde se logra consenso, al entender la gran complejidad que encierra este proceso y la influencia que ejerce en la historia de la humanidad. Se reconoce (Chaos, 2005, p. 3) la necesidad de

analizar la historia urbana dentro del marco de los factores condicionantes donde, el medio geográfico (sobre el cual se funda la ciudad), la población (el hombre como transformador del medio) y el marco bistórico específico (la economía, la política, la ideología y la sociedad); establecen las condiciones que permiten llegar a una determinada estructura fisica.

El hecho urbano ha ocupado un lugar especial en diversas disciplinas como la geografía, la historia, la arquitectura y las ciencias sociales, entre otras. Recientemente se le atribuye a la geografía urbana un roll importante por su objeto de estudio ya que el mismo aborda "lo urbano como sistema complejo, sus leyes y principios, así como los fenómenos y procesos que se generan desde y hacia los asentamientos, así como los que se manifiestan en el interior de los mismos" (González, 2016, p. 11).

Para la arquitectura se considera que el estudio de la morfología urbana (Colectivo de autores, 1991, p. 35) contempla "un conjunto de análisis dirigidos a definir, en términos concretos, las características formales de la ciudad producidas por un desarrollo histórico particular" a partir de entender que las tipologías urbanas son el resultado de los valores sociales y los significados que imperan en el proceso de gestación de las ciudades. En la morfología urbana intervienen diversos factores socio-urbanísticos como las características históricas y geográficas, las relaciones establecidas entre centro y periferia, la valorización y desvalorización simbólica del sitio por los hombres que lo habitan y las imágenes de las que se apropian.

De igual forma desde las diversas disciplinas se han desarrollado varias metodologías para el estudio del proceso de urbanización de las ciudades, así como de su organización espacial. Los planteos teóricos realizados han estado marcados también por las diferentes posiciones ideológicas. Algunos autores (Fourquet, 1978; Bourdieu, 1993; Stevens, 1998) reconocen relaciones que disuelven las fronteras de estos análisis.

Para Fourquet (1978) una fuerza social cualquiera ejerce una forma de dominación y las reglas de su funcionamiento, lo cual permite pensar el espacio urbano en términos de sistema de relaciones. Bourdieu (1993), ha estudiado las relaciones entre las estructuras del espacio físico (urbano) y las del espacio social. Para él, el espacio físico funciona como simbolización espontánea del espacio social. Como plantea Stevens (1998) hay una base social en el proceso de creación de las ciudades en el que influye el entorno social y las estructuras donde se reconoce y en ese proceso se producen los símbolos que permiten mantener el orden social vigente y estos símbolos forman parte importante de la cultura material que a su vez crea, legitima y reproduce la estructura social. Es por ello que,

Puede afirmarse que la ciudad es una representación del poder en tanto que la apropiación del espacio, por los hombres, ha estado también, a lo largo de la bistoria, estrechamente relacionado con el ejercicio de este. En ese sentido resulta válido el análisis de la estructura física de las ciudades, partiendo de su reconstrucción histórica, sobre la base de considerar que las relaciones sociales y las estructuras del poder exigen una determinada forma urbana (Chaos, 2005, p. 6).

Si bien se ha manejado la presencia del poder, a través de la estructura física de las ciudades, también se han considerado a estas como el instrumento de dominación y el marco por excelencia para su ejercicio eficaz. Esa es la razón fundamental por la que los espacios físicos se convierten en los lugares donde se organiza y se ejerce el poder de forma sutil o enmascarada a través de los espacios arquitectónicos y urbanos. Es lo que Bourdieu (1993) ha dado en llamar "efectos de lugar”. Según Chaos (2005, p. 21)

En cada etapa histórica la arquitectura ha estado y está condicionada por las relaciones de producción existentes, de alli que las obras arquitectónicas estén a su vez condicionadas por las posibilidades económicas y la ideología de los que intervienen en su concepción, diseño y uso. En este sentido el poder que ejercen los grupos económicos dominantes es decisivo en las realizaciones tanto urbanas como arquitectónicas. El papel de la arquitectura como expresión de poder se manifiesta en el control que ejerce la estructura social en un lugar y tiempo concreto sobre los recursos económicos disponibles para la producción arquitectónica.

Chaos (2015, p. 665) también apunta que

En la conformación de la estructura de la ciudad predominan un grupo de relaciones funcionales que pueden verse modificadas por la ocurrencia de 
disimiles hechos, un incendio, el despoblamiento, los ataques de piratas, las epidemias o simplemente la voluntad de un poderoso vecino, que amparado en su poder económico o en los cargos públicos, establecen, permiten y finalmente se benefician de la falta de reglamentaciones, en cuanto a la concesión de terrenos; todas ellas resultan causas suficientes para alterar de forma radical un emplazamiento urbano. Es por ello que la historia vinculada a un paisaje que interactúa con el hombre, va modificando los espacios físicos y factores de carácter politico, económico, social, ideológico-cultural, entre otros influyen $y$ determinan en la formación $y$ consolidación de un asentamiento.

Según González (2018, p. 2),

El espacio urbano actual es el resultado de un proceso de diferenciación socio espacial, que obedece a los procesos económicos y sociales ocurridos en el pasado y el presente. La ciudad fortalece y/o reacomoda lamemoria de su proceso histórico de consolidación espacial, a la vez que pueden reemerger o emerger nuevas disparidades de manera coyuntural.

En la actualidad una vez que se ha reconocido la importancia del estudio del hecho urbano desde sus inicios, preocupan también los problemas actuales a los que se enfrentan las ciudades. Ha sido reconocido (Chaos y Marichal, 2015) que el nivel de autorrealización de un individuo a lo largo de su vida depende críticamente de la calidad del entorno en que se desenvuelve; se establece así, una relación entre el medio físico y el desarrollo humano personal, que está condicionado por la satisfacción de sus necesidades materiales y espirituales expresadas en estilos de vida cuya característica dominante en los últimos años ha sido lamentablemente el consumismo excesivo, promovido por la teoría económica neoliberal.

Como algunos autores afirman (Pogolotti, 2015), hoy día, "las urbes sobredimensionadas padecen las consecuencias de la alta contaminación y la insostenibilidad económica, después de haber pagado un alto costo por el derrumbe de sus centros históricos y de mucho de sus valores intangibles". Varios Documentos Internacionales sobre conservación del patrimonio alertan al respecto, así por ejemplo,

La resolución de Brujas, en 1975, deja muy en claro el interés por sobre todas las cosas de mantener el respeto a la población que habita en ellos, basándose en que la ciudad es el fundamento del entorno construido por el hombre, siendo el reflejo de toda su existencia, dejando en ella su cultura, tradiciones, historia e identidad (Falls, Chaos, Amaizy Peláez, 2019, p. 242).

Se coincide con Almeida (2015, p. 247) cuando plantea que

La ciudad como organismo vivo y ecosistema articulador de las actividades socio-económicas del hombre, sufre cíclicas transformaciones en busca de adaptabilidad y eficiencia ante los retos y las necesidades que su propia evolución le impone. Uno de los desafíos de las ciudades del siglo XXI está en lograr una evolución capaz de respetar y renovar identidades, tradiciones culturales y modos de vida ante la intensa aceleración de la globalización (...)

En este sentido las acciones de conservación y la concertación de políticas públicas centradas en el hombre como recurso fundamental de preservación patrimonial, tienen una importancia capital, pues como dijera Martí (1988, p. 336) “el espíritu de los hombres flota sobre la tierra en que vivieron, y se les respira." De allí que el objetivo esencial sea demostrar a través del análisis del surgimiento y evolución de Santa María del Puerto del Príncipe, que la historia de las ciudades es la historia del hombre, vinculada a un contexto geográfico, condicionado por factores económicos, políticos, sociales e ideológico culturales. A la vez la investigación busca evidenciar que la ciudad y su arquitectura como parte de la cultura material de la sociedad y de su memoria colectiva no son estáticas, sino que sufren constantes modificaciones, las que deben estar encaminadas a enriquecer la identidad urbana.

La evolución de una ciudad debe lograrse sin agredir los significados que han tardado siglos en su conformación y que actualmente constituyen parte esencial de su identidad cultural, pues reflejan la estratificación histórica de valores y atributos culturales y naturales, que tienen una fuerte repercusión simbólica para la sociedad. De esta forma las nuevas prácticas urbanas que se generan para satisfacer usos y necesidades actuales deben fomentar formas positivas de comportamiento cívico que garanticen la preservación de los valores y símbolos como un proceso dialéctico de construcción de identidades. (2007)

Para ello como bien plantea el ICOMOS

El análisis morfológico, el estudio histórico, social y cultural de la ciudad, de la idiosincrasia de la sociedad que lo realizó, asi como de sus parámetros estéticos, ayudan a definir aquellos elementos del espacio urbano, de su paisaje, que marcan el carácter de la ciudad, forman parte de su memoria y de la 
identidad personal y colectiva de sus habitantes y por ello debe conservarse.

\section{La incidencia del medio geográfico, Santa María del Puerto del Príncipe}

Cada ciudad posee una fisonomía propia, condicionada por el sitio de su emplazamiento y por las respuestas dadas por el hombre a sus necesidades a lo largo de la historia. Es entonces cuando puede hablarse de la ciudad como la forma y el símbolo de una relación social integrada (Mumford, 1966). Para el caso de las nuevas fundaciones americanas, Chaos, M. T. (2005, p. $21-$ 22) plantea que

\begin{abstract}
Aunque sean diversos los argumentos, no caben dudas de que el llamado modelo de ciudad iberoamericana fue un fenómeno único, de conquista y colonización y por tanto, la más clara demostración de poder, sea cual fuese su influencia.

Con el acto de fundación de la ciudad, se afirma la soberanía de la tierra; y al agrupar en ella a la población, se evidencia que el poder se sustenta en una base urbana. No era sólo el acto en si mismo, porque babia un contenido simbólico: desde la elección del sitio, la colocación de la cruv, la misa y el festejo del día, el hombre comienza a elaborar las ideas de estar creando un nuevo espacio; y en la medida en que esta imagen se refuerza, se convierte en algo trascendente, sagrado.
\end{abstract}

Pero a la vez, la ciudad estaba destinada a cumplir con múltiples funciones en la estrategia colonizadora: "como centro administrativo y local, como medio de sometimiento de la población indígena, como puente para penetraciones más profundas en el territorio, como polo de concentración de actividades de toda índole y como foco de control de la propiedad del suelo" (De Terán, 1989, p. 53).

Fueron múltiples las normativas y recomendaciones acerca de cómo llevar a cabo la fundación de las nuevas ciudades. En un inicio, puede decirse que los textos resultaron imprecisos, pues el desconocimiento de los sitios al otro lado del mar, impidió tener una idea clara de tal empresa. Una vez fundados los primeros asentamientos, las normativas evolucionaron hacia aspectos más específicos y concretos. Es en el año 1573 que Felipe II, promulga el texto de las Ordenanzas de descubrimiento, nueva población y pacificación y hace claras precisiones con relación a los requisitos del sitio, la jerarquía del asentamiento y de las autoridades, sobre el uso, distribución y tenencia de las tierras, y sobre aspectos de la morfología urbana, aunque para la fecha ya la mayoría de las ciudades en el Nuevo Mundo, estaban fundadas.

Según Morales (1999) fue Fernando El Católico el primero en interesarse por Cuba y se lo manifestó en una carta a Nicolás de Ovando en el año 1504. Desde ese primer acercamiento inició un proceso de descubrimiento y ocupación del territorio de la isla. Según González (2016, p. 217), "la formación del territorio de la ciudad se produce a través de un proceso de expansión física del mismo". En el caso cubano, con la llegada de los conquistadores, la isla de Cuba, es considerada una sola provincia y en ella funda Velázquez las siete primeras villas (Fig. 1). Así permaneció la isla hasta el 8 de octubre de 1607 en que, por Real Decreto se hizo la primera división de su territorio y se fundaron dos gobiernos independientes, el de La Habana y el de Santiago de Cuba. Santa María del Puerto del Príncipe estaba situada más bien al centro de todo el territorio, entre ambos gobiernos.

Las investigaciones llevadas a cabo sobre el proceso de fundación de la villa de Santa María del Puerto del Príncipe y las condicionantes que determinaron su morfología urbana (Gómez, 1986y Chaos, 2005), han abordado las diversas hipótesis e indagado en fuentes documentales y de archivo que arrojan luz sobre los hechos. El análisis del medio geográfico, en las zonas donde se produjeron los asentamientos sucesivos de la villa de Santa María del Puerto del Príncipe, describen las características de su comportamiento. Su primer asentamiento estuvo ubicado en la costa norte, de la que se ha dicho que estaba formada por extensas playas de arena intercaladas de terrenos pantanosos (Barrios, 1881), constituida en muchas partes por arrecifes, con una larga cadena de cayos y un litoral bajo y pantanoso. El lugar elegido fue una lengüeta de tierra en el interior de la Bahía de Nuevitas, denominada Punta del Güincho, a la entrada de la ensenada de Mayanabo. La Doctora Gómez Consuegra, según fuentes del Archivo Nacional de España (ANE) cita, al referirse al emplazamiento de este primer asentamiento:

El establecimiento que existe en el día se reduce a 15 o 20 casas de paja situadas en terreno nada ventajoso ni cómodo por hallarse en una angostura de dos lomas que le hacen búmedo y precipitado a más de que no proporciona capacidad suficiente para extender la población.

Por su parte Juárez (1929, p. 21) refiere que, a la llegada de los primeros colonos, estos "observaron que carecían de agua y pastos para el ganado, aparte que la tierra, de naturaleza caliza y muy estéril, no reunía condiciones apropiadas para la siembra". Morell de Santa Cruz (1985, p. 65) relata la suerte de la villa de estar ubicada en 
"terreno dominante desde donde se descubre el mar, pero [...muy] infestado de mosquitos". Otros autores (García, 1990, p. 3) al referirse al asentamiento, han afirmado "Cuan fallido amago de colonizar tan inhóspitos predios, estériles y desprovistos de agua potable y de otros elementos naturales indispensables". para su fomento y crecimiento. También fueron encontradas piedras tintóreas (usadas para pintarse el cuerpo) lo que permitía librarse de las picaduras de los insectos. Al referirse a ello, Juárez (1929, p. 21) apuntaba que

Figura 1 - Primeras villas fundadas en la isla de Cuba

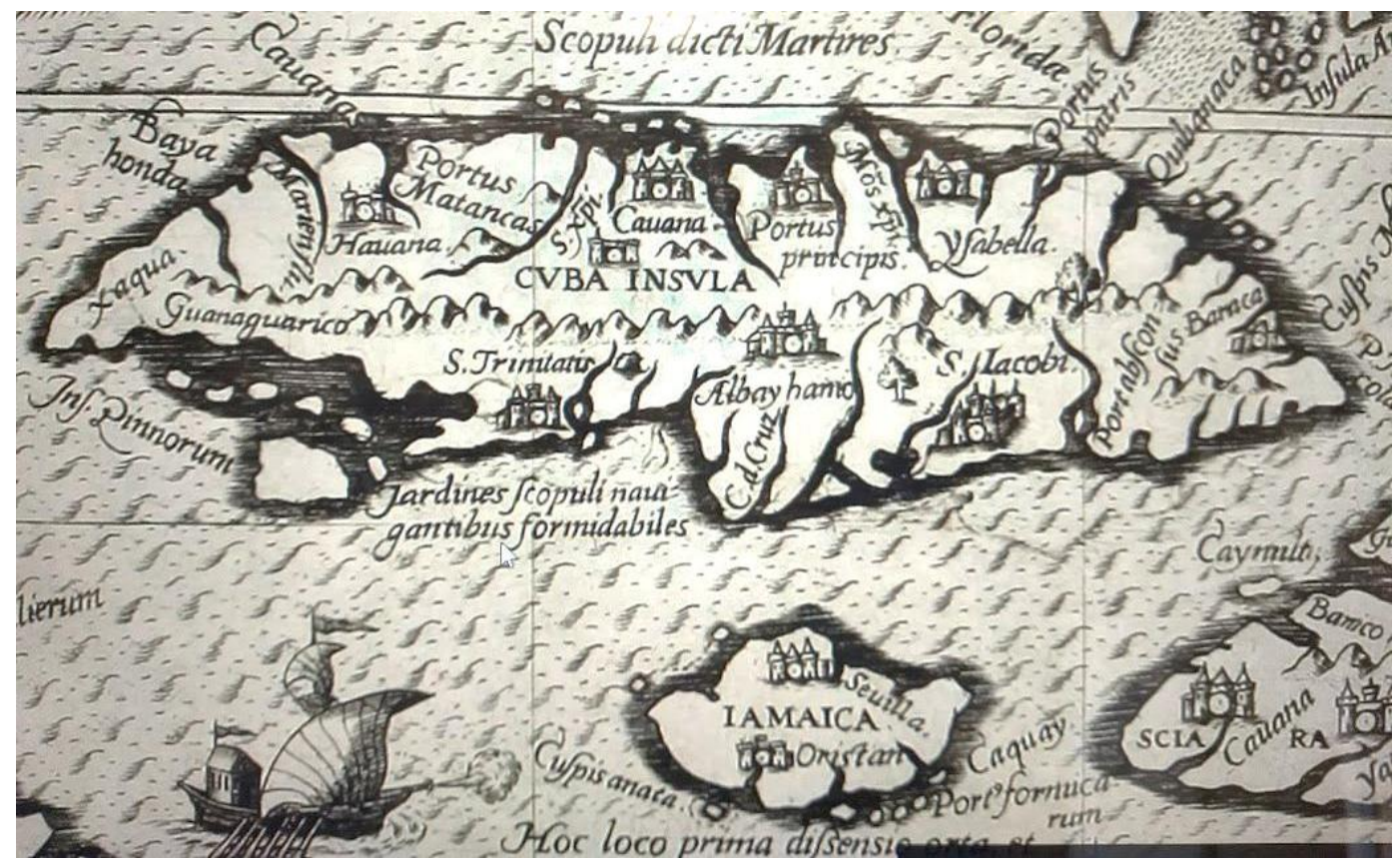

Fuente: Chaos, M. T. (2005, p. 37). Biblioteca Nacional de Cuba “José Martí". BNCJM. Mapoteca. Detalle del plano de la Isla de Cuba. Copia del original, Occidentalis Americae partis, velearum Regionum quas Christophorus Columbus primu detexit. Tabula Chorographicae multorum Auctorum scriptis, praesertim vero ex Hieronymi Benzoni. Théodore de Bry, Amsterdam, 1594. (Cortesía Lourdes Gómez Consuegra).

No caben dudas de que los inconvenientes presentados por el medio geográfico -aunque no se excluyen otros factores-, determinó el traslado de la villa a su segundo asentamiento. Esta vez, el lugar elegido sería un cacicazgo aborigen denominado Caonao, en las márgenes de un río del mismo nombre. La ubicación algo distante de la anterior, hacia el oeste, ocurriría un poco más alejada de la costa contraria a las indicaciones de la Corona. Se salvaba así la carencia de una fuente de abasto de agua, porque el río Caonao era uno de los más caudalosos de la zona. Según Juárez (1929) los indios de aquella zona vivían en comunidad paradisíaca, por lo que la región debió ser de muy buenos suelos para el cultivo y pasto del ganado.

Cuando se analizó la población (Chaos, 2005, pp. 111-122), en el caso del grupo subtaíno que se corresponde con los asentados hacia el norte, se pudo constatar la presencia de cuarcita (roca silícea utilizada para la construcción de edificaciones) en los suelos analizados, por lo que el lugar elegido para el segundo asentamiento, de haberse mantenido, contaba con un buen material
Con respecto a la abundancia de "bichitos", como se le dice a la "plaga" en las playas norteñas de Camagüey, nada ganaría la población con el cambio de lugar, porque también los había en Caonao, aunque no en tan crecido número como en Nuevitas.

El último asentamiento se produjo entre los ríos Tínima y Hatibonico. Barrios (1881, p. 23) describió el medio geográfico de este tercer asentamiento como

Una comarca excesivamente llana, en la que el paisaje es uniformemente sabanas, monte y potrero, con lluvias torrenciales que socavan grandes barrancos casi secos en invierno, impetuosos y temibles torrentes en verano, cuyo cauce encajonado suele no obedecer a los movimientos generales del terreno.

Estas características hicieron posible que el medio geográfico se convirtiera en la principal base económica de la ciudad. De la Cruz (1844, p. 3) refiere que "el terreno es árido, silíceo y arcilloso, 
circundado por los ríos Tínima y Hatibonico que presentan sus márgenes limpias y sus aguas sirven todo el tiempo para el uso y abasto de los vecinos". Según Luaces (1946) las llanuras poseen características que las hacen de gran calidad para el cultivo y la ganadería. Los estudios realizados en esta zona por la Academia de Ciencias de Cuba (ACC, p. 2) han podido determinar que

\section{su topografía propició que a través de la historia, grandes áreas fueran dedicadas al fomento de la ganadería y al cultivo de la caña de azúcar en detrimento del bosque, que en gran medida fue sustituido por la extensa sabana antrópica que constituye hoy el elemento más sobresaliente del paisaje.}

Este último asentamiento ocupó un terreno que contó con varias lagunas, algunas de ellas hasta el siglo XVIII, las fuentes escritas del Archivo Histórico Provincial de Camagüey (AHPC, Fondo Personal Jorge Juárez Cano. Carpeta No. 5. Folio 5) refieren que eran navegables y ricas en biajacas. Esta pudo ser una las razones para la ubicación del centro de la villa en la zona más llana y elevada. En cuanto a la topografía, un análisis actual de las curvas de nivel permite determinar que la zona de la plaza mayor en cualquiera de las posibles ubicaciones de la villa después del último traslado hacia el centro del territorio, estaba en una cota superior que desciende hacia ambos ríos; lo que permitía que el agua de las lluvias corriera libre hacia ellos, siendo un sitio favorable para la ubicación del núcleo urbano. El terreno arcilloso propició el crecimiento acelerado de la villa que pudo contar con importantes tejares donde se elaboraron tejas y ladrillos de toda clase y grandes tinajones para el depósito de las aguas.

\section{Las haciendas y su efecto en la arquitectura urbana}

Según González (2016, p. 168) el sistema de asentamientos poblacionales de un territorio es la "expresión de los valores y desarrollo de su sociedad y economía”. Unido a ello, es posible afirmar que en el desarrollo y consolidación de un asentamiento hay efectos espaciales y territoriales de los procesos socioeconómicos que modifican las relaciones de interdependencia que se dan en el decursar histórico de las ciudades. De esta forma se produce lo que Racionero (1986) plantea como proceso de selección espacial que ocurre primero, atendiendo a las actividades predominantes y luego de selección temporal, donde tienen un peso los factores histórico-económicos que favorecen su crecimiento o estancamiento.
Como ha planteado Pierre George (1969, p. 204) "La ciudad no se justifica ni se caracteriza más que por el lugar que ocupan sus habitantes activos dentro de un sistema de relaciones económicas y sociales". Atendiendo a lo anterior Chaos (2005) afirma que si bien la villa de Santa María del Puerto del Príncipe se desarrolló como ciudad embrionaria, no es menos cierto que creó en su evolución el medio rural del que luego se nutrió. La economía de la villa se sustentó en una considerable producción agro-ganadera perteneciente a las principales familias, quienes además de contar con sus propiedades urbanas, contaron con haciendas en la periferia de la ciudad, lo cual permitió establecer relaciones y dependencias. Se conoce que las familias más importantes de la villa entre los siglos XVI y XVIII, fueron los Porcayo de Figueroa, Cerda Sotomayor, De Ovando, De Consuegra, Del Toro, De la Torre, Miranda, Zayas, Recio, Hidalgo y Agramonte, entre otras (Torres, 1888; De Santa Cruz, 1943).

A partir de la dinámica económica que se consolidó desde el siglo XVI y durante todo el XVIII se produce un efecto reciproco, por un lado se desarrolló el comercio que condicionó el auge de la ciudad y, por otro, el poder económico en manos de una clase social rica asentada en los alrededores del núcleo de poder, fruto entre otras cosas de los beneficios del entorno rural favorable para el cultivo y la ganadería; que se tradujo en crecimiento y prosperidad del centro urbano. Chaos $(2005,2011)$ plantea que las haciendas fueron el elemento fundamental agro económico de acumulación de capital que permitió el desarrollo de la arquitectura urbana.

Para corroborar lo anterior debe mencionarse que la Corona para el año 1532, había concedido al Ayuntamiento de la Isla, la facultad de mercedar tierras a los vecinos para la formación de toda clase de fincas rústicas. A fines del siglo XVI, no quedaba en Puerto Príncipe terreno por repartir, incluyendo mercedes en los territorios de Bayamo y Sancti Spíritus. Fue tan importante para el crecimiento de la villa el fomento de sus haciendas que, desde la temprana fecha de 1552, se tomaron medidas para la protección de la ganadería, prohibiéndose matar el ganado que entrara a las labranzas (De la Cruz, 1844).

Desde la primera mitad del siglo XVI, las fuentes escritas, dan cuenta de las propiedades rurales de los principales vecinos. Algunas refieren una gran hacienda ubicada al norte con un fértil arroyo y donde se construyó el primer molino de maíz y trigo (AHPC, Fondo Personal Juárez, J. Biografías. Caja No. 52. Expediente 159) y otra en el embarcadero de Vertientes llamada "Santa María” (AHPC, Fondo Personal Juárez, J. Carpeta 
No. 3). Otras haciendas también se ubicaron en los alrededores de la villa, como la hacienda Manga Larga, fundada antes de 1601 (AHPC, Fondo Personal Juárez, J. Legajo 5). Para la fecha de 1616, no debieron ser pocas las haciendas o fincas en los alrededores de la villa, pues se sabe por fuentes escritas (De la Cruz, 1844) que las inundaciones ocurridas en esa fecha causaron daños y hasta la pérdida de grandes fincas y ganado.

En 1723, se dice que Puerto Príncipe contaba con unas 800 fincasentre hatos, corrales, cercados de mulos y haciendas de labor (Juárez, 1929, p. 60). Ello permitió que todo el consumo de la población fuera producto de sus tierras y que alcanzara además para otras villas vecinas y para el comercio de contrabando. En 1756, el obispo Morell de Santa Cruz (1985, p.81), en su visita pastoral, da cuenta del desarrollo rural de la villa, manifestando que las haciendas de la jurisdicción suman 56 ingenios de azúcar, 77 hatos de ganado mayor, 212 sitios de ganado mayor y menor, 23 corrales de menor, 284 estancias de casabe y legumbres, 60 tejares y 8 tenerías para curtido. fuentes que abordan los primeros años del siglo XIX, así lo atestiguan (Fig. 2). La ciudad contaba con 1027 cuadras para un aproximado de 256 manzanas y 120 calles y callejuelas. El fondo habitacional era de 3640 viviendas, de ellas 48 de alto, 3362 eran bajas y de tejas y sólo 194 aún eran de guano (AHPC, Fondo Personal Jorge Juárez Cano. Carpeta No. 15).

\section{Transformación material y simbólica del espacio. El modelo de ciudad que aspiramos}

$\mathrm{Si}$ bien es cierto que muchos de los primeros asentamientos fundados en el Nuevo Continente, no tuvieron una orientación previa y que se adaptaron al medio geográfico preexistente, es posible afirmar que en su evolución ocurrió una transformación material y simbólica del espacio. El trazado irregular de la ciudad de Camagüey difiere de la mayoría de las fundaciones caracterizadas por una trama regular en cuadrículas. Su caracterización

Figura 2 - Desarrollo urbano de Puerto Príncipe. Grabado de la ciudad, finales del siglo XVIII

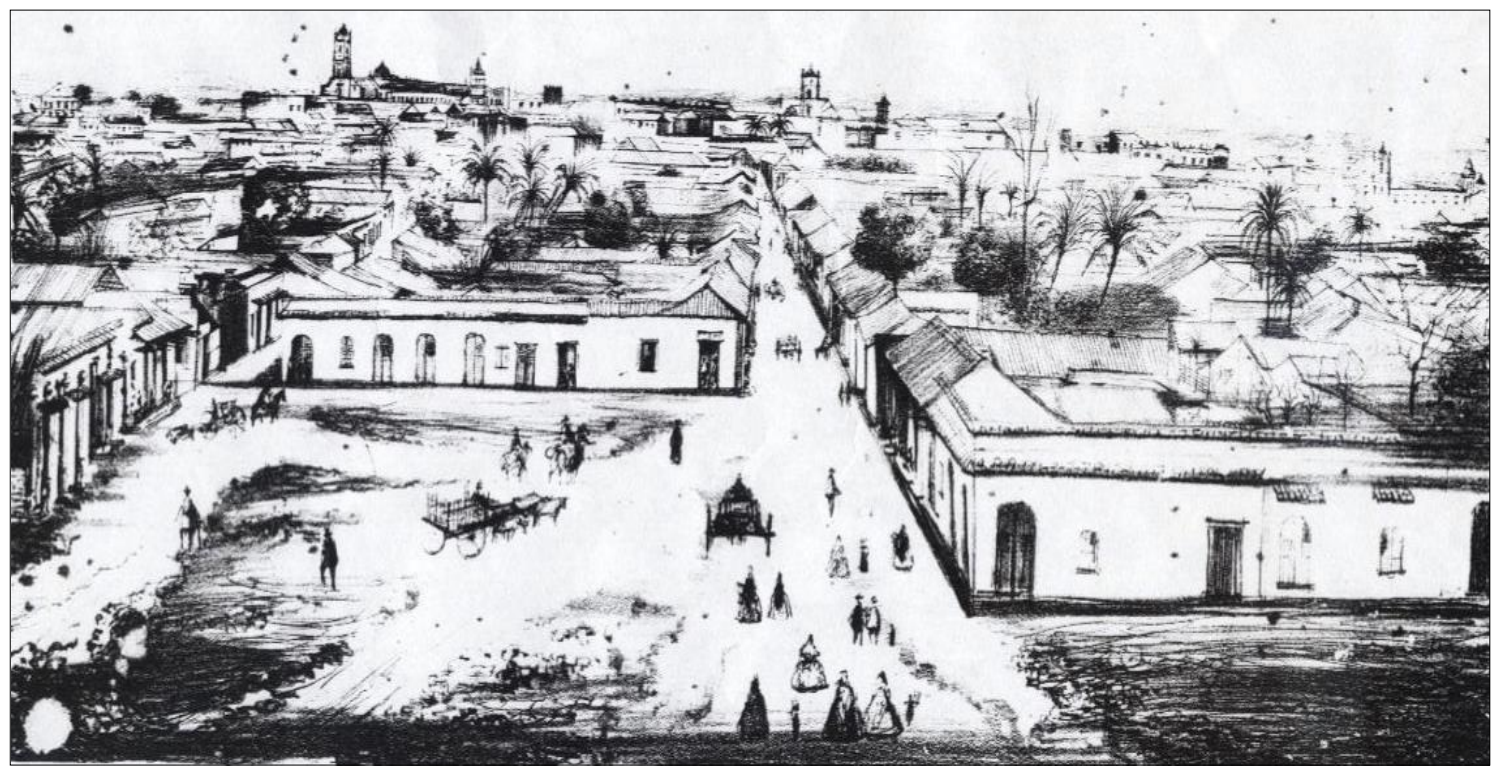

Fuente: BNCJM. Fondo de Grabados.

El siglo XVIII no cabe dudas que fue para Puerto Príncipe, de una economía muy estable que alcanzó a beneficiar el desarrollo de la arquitectura urbana, la que dejó de ser precaria para ser cada vez más sólida. El historiador Arrate plantea que, para el año 1761, las principales familias de la villa que eran poseedoras de haciendas realizaron importantes inversiones en edificios de vivienda. A la economía de ellas, se debió también el crecimiento de las construcciones religiosas y la mejora sustancial de las existentes. Puede afirmarse que elcrecimiento urbano fue notable (Fig. 2), las tipológica-urbana es el resultado de una estructura formada por calles estrechas y sinuosas y un conjunto de plazas y plazuelas, en ocasiones resultado de la confluencia de varias vías o el ensanchamiento de estas. Dichos espacios permiten percibir los más diversos emplazamientos urbanos, muchos de los cuales están jerarquizados por las iglesias que definen, a través de torres y cúpulas, el perfil de la ciudad.

La ciudad segregada expresó las relaciones de poder, las que a su vez condicionaron la morfología urbana generando como tipología un 
modelo irregular, reconocido por algunos autores como espontáneo (González, 2016). En el análisis del resultado final de la trama de la villa subyace la voluntad de sus moradores, quienes amparados en su poder económico y en los cargos públicos, establecieron, permitieron y finalmente se beneficiaron de la falta de reglamentaciones, en cuanto a la concesión de terrenos. Se produjo un crecimiento por extensión marcado por la ubicación de las edificaciones del repertorio religioso y un reforzamiento de la centralidad de la ciudad, o lo que es igual del núcleo de poder. Ello fue posible por la presencia de los símbolos de poder como la iglesia, el cabildo y las viviendas de la élite principeña y de las acciones simbólicas, o sea, de los usos del espacio central para fiestas, procesiones, desfiles militares y demás actividades que garantizaron que los grupos sociales defendieran este espacio como "su" espacio vital. Tanto los símbolos como las acciones simbólicas se encargaron de mantener el orden social establecido demostrando que el ejercicio del poder de forma efectiva fue posible gracias a la actuación en el campo de lo simbólico (Chaos, 2005).

Al analizar el crecimiento y organización espacial de una ciudad se evidencian transformaciones marcadas por los cambios que ocurren en el orden social. Una lectura al plano de la ciudad de Camagüey (Chaos y Marichal, 2015) permite apreciar que el centro tradicional muestra un tejido irregular en el que se insertan numerosas plazas y plazuelas, único en toda la estructura urbana (desarrollo urbano entre 1528-1900) (Chaos, 2005) rodeado por un tejido compacto que tiene como base la retícula y que aunque varía su tamaño y orientación, mantiene la continuidad y unidad (desarrollo urbano entre 1900-1931). A este espacio le continúa otro, que se caracteriza por la dispersión. A lo largo de ejes viales importantes se han adosado zonas residenciales que mantienen la retícula en su trazado, en contraste con otras que han crecido espontáneamente y han asumido un trazado irregular. Tiene en su borde exterior grandes instalaciones industriales y educacionales que han quedado aisladas del resto de la estructura urbana (desarrollo urbano entre 1931-2004) (Marichal, 2006).

Según Chaos y Marichal (2015) las etapas de fuertes cambios estructurales provocaron procesos de densificación de la trama existente, mientras que las etapas de auge económico generaron grandes expansiones urbanas. En la ciudad se fusionan pasado y presente, pero es por sobre todo un espacio para el intercambio social, reflejo de la yuxtaposición de épocas y con la flexibilidad necesaria para asumir nuevos elementos de significación que enriquezcan su identidad urbana.
Todo esto se sintetiza en un modelo de estructuración radio concéntrico y disperso, en el que predominan cinco corredores radiales de intenso desarrollo que guian la expansión del núcleo urbano conformado por cinturones continuos de vivienda en la zona intermedia y de industrias y grandes instalaciones de servicios en la zona externa, que van cerrando las zonas centrales, donde se localiza su único centro de servicios. Prevalece un tejido continuo con grado de consolidación alto y medio en las áreas central y media que se diluye hacia la periferia (...) (Chaos y Marichal, 2015, p. 26)

Los procesos de significaciones están siempre circunscritos al ámbito social. Para Henri Lefebvre (1972) lo urbano no se limita a la morfología urbana; sino que se trata de algo mucho más complejo que es la manera de vivir una sociedad a partir de la base económica, social y cultural.Se produce así una relación esencial entre espacio-hombre, por un lado ese espacio vital adquiere significados y a la vez "cada hombre vale por el lugar en donde está: su valor como productor, consumidor y ciudadano depende de su localización en el territorio" (Santos, M., 2007, p. 107). Según Costa, E. (2018) "Más que residir, las generaciones sucesivas que habitan el patrimonio reconocen su historia y memoria desde una conciencia espacial afectiva fortalecida por tradiciones locales." Las imágenes atestiguan los cambios producidos, pero también la permanencia de determinados símbolos, esos que pasan a formar parte de la memoria colectiva (Fig. 3).

La historia de las ciudades tiene un fuerte componente ideológico derivado de posturas y concepciones de quienes la escriben, es por ello que "leer en la piedra" y asegurar la memoria a partir de símbolos concretos constituye una alternativa de preservación patrimonial donde el hombre constituye su elemento esencial. Para Serrano y Köster (2016, p. 6)

\section{la identificación y la participación, la interiorización por parte de los residentes son elementos fundamentales en el largo plazo. La sostenibilidad discursiva, por tanto, sólo se puede mantener en el caso de que los mensajes simbólicos sean encarnados y trenzados con la efectiva identificación cultural de los ciudadanos y los usos que éstos hacen del espacio urbano.}

Duany y PlaterZyberk (2003, p. 9) sostienen que "el futuro del urbanismo pertenecerá a ciudades como las que ya existen en Cuba: compactas, caminables, de uso mixto y adaptable al tránsito público". Esta aseveración pasa por un concepto esencial que atiende varias dimensiones: 
Figura 3 - Iglesia Nuestra Señora de la Soledad. Permanencia de símbolos

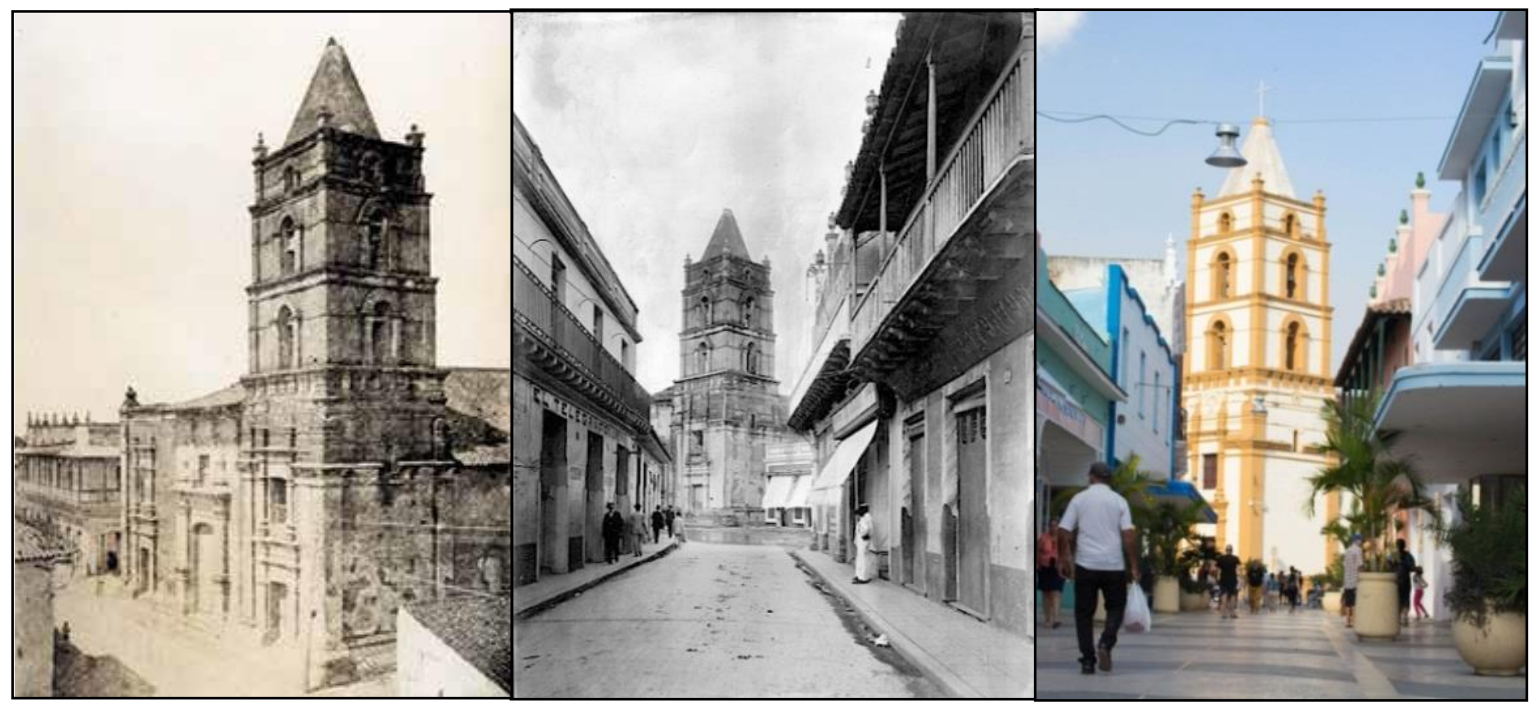

Fuente: De izquierda a derecha. García (2012), Crespo (2018), Cortesía Larissa Alves de Sousa

la identidad cultural. Para Chaos (2011, p. 162) la identidad

es una construcción social vinculada a los acontecimientos que ocurren en el seno de la propia comunidad. En este sentido, es preciso buscar elementos de cohesión social en torno a sus valores y simbolos. La arquitectura constituye probablemente una de las expresiones del genio humano con mayor significación social. Su origen es interpretado como el signo más radicalmente distintivo del origen de la civilización y de la historia misma.

En este sentido para Espinosa y Cortés (2015, p. 229) la arquitectura como ciencia "debe brindar las condiciones adecuadas para el habitante y su relación con el entorno, por lo que debe ser capaz de apropiarse del territorio (...)". Urge considerar el acelerado crecimiento de la población para el caso de América Latina y el Caribe que se proyecta alcanzar 661 millones en 2020 (CEPAL, 2012), lo que evidencia la necesidad de políticas públicas centradas en las relaciones hombreterritorio. Si a ello se suma la vulnerabilidad de las ciudades históricas con núcleos monumentales, la percepción del riesgo debe alcanzar dimensiones mayores, pues la pérdida de su patrimonio implica la desaparición de la memoria colectiva. Es por ello que

El diseño de políticas públicas debe privilegiar a los núcleos monumentales y su identidad, sobre la premisa de una planeación integral que busque la mejor integración de los gobiernos locales, la población residente, los profesionales, las universidades y todos los agentes y actores implicados en el desarollo urbano con objetivos claros que propicien la recuperación de la imagen urbana y el bienestar social, económico y cultural de sus habitantes, pues no babrá futuro sin presente" (Chaos, M. T., Arnaiz, M.., Falls, D., Sóñora, B., 2019, p. 303). (Fig. 4)

Sin embargo, como bien ha planteado Costa (2018) "El número exiguo de fuentes acerca de riesgos y potenciales de preservación en América Latina y el Caribe corresponde con la fragilidad de las políticas públicas relacionadas con la gestión de riesgos patrimoniales en el continente". Las políticas públicas deben contener un conjunto de acciones que emanen de la adecuada planificación para garantizar la conservación y el uso público de los bienes patrimoniales que integran la riqueza cultural de un pueblo y que deben estar al alcance de todos. Para ello según afirma Garré, F. (2001)

La sociedad en su conjunto a través de sus referentes e instituciones es la que debe determinar cuáles son sus bienes patrimoniales naturales, urbanos $y$ arquitectónicos. Es responsabilidad de los gobiernos, con sus instrumentos jurídicos legales generar una malla articuladora de preservación, custodia y tutela dinámica del patrimonio arquitectónico urbano.

Chaos (2018, p. 24) plantea que

El patrimonio cultural refleja la vida de la comunidad, su historia e identidad. Su preservación ayuda a reconstruir comunidades desmembradas, a restablecer su identidad, a crear un vínculo con su pasado y a crear un vínculo entre el pasado, el presente y el futuro. El patrimonio y la identidad cultural no son elementos estáticos, sino entidades 
Figura 4 - El papel de los profesionales y las universidades. Trabajo de campo. Parque Agramonte, antigua Plaza Mayor. Centro histórico de Camagüey

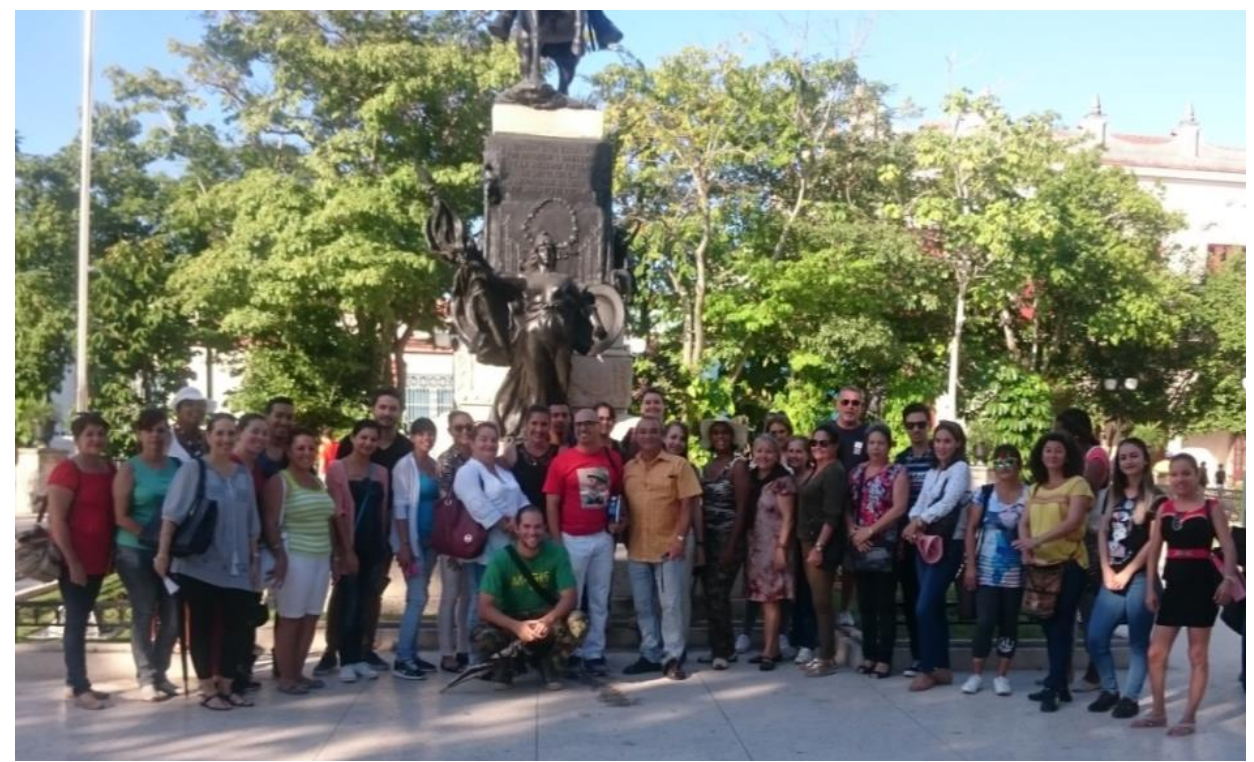

Fuente: Archivo Centro de Estudios de Conservación y Desarrollo de las Construcciones. CECODEC. Camagüey, Cuba. 2018

sujetas a permanentes cambios, están condicionadas por factores externos y por la continua retroalimentación entre ambos.

La ciudad del siglo XXI se enfrenta a un problema primario el "Nuevo desarrollismo urbano basado en una política de construir cada vez más edificaciones, más grandes, más costosas, más inteligentes: más modernas" (Pino, 2018, p. 1); pero ello muchas veces conduce al abandono de las zonas habitacionales. Estos aspectos como plantea el autor "son parte de una política urbana de corte neoliberal orientada casi exclusivamente al mejoramiento de las condiciones económicas del capital en la ciudad, en detrimento de la ciudad y sus habitantes" (Pino, 2018, p. 2).
Si ha sido reconocido (Boisier, 1999, p. 25) que "el nivel de autorrealización de un individuo a lo largo de su vida depende críticamente de la calidad del entorno en que se desenvuelve"; no hay duda de la urgente necesidad de operar el cambio: de la ciudad competitiva, global, innovadora, inteligente; a la ciudad humana, caminable, inclusiva, justa. $\mathrm{Al}$ insistir en la modernización de la ciudad a costa de la población y el ambiente, se corre el peligro de avanzar en su deterioro hasta el punto en que ya no haya retorno. La activación del espacio para que en el dialoguen las actividades cotidianas con otras deportivas, culturales, con proyectos comunitarios y se garantice la permanencia de las viviendas de los vecinos es una utopía realizable (Fig. 5).

Figura 5 - Activación del espacio. Plazuela Rosa La Bayamesa. Centro histórico de Camagüey

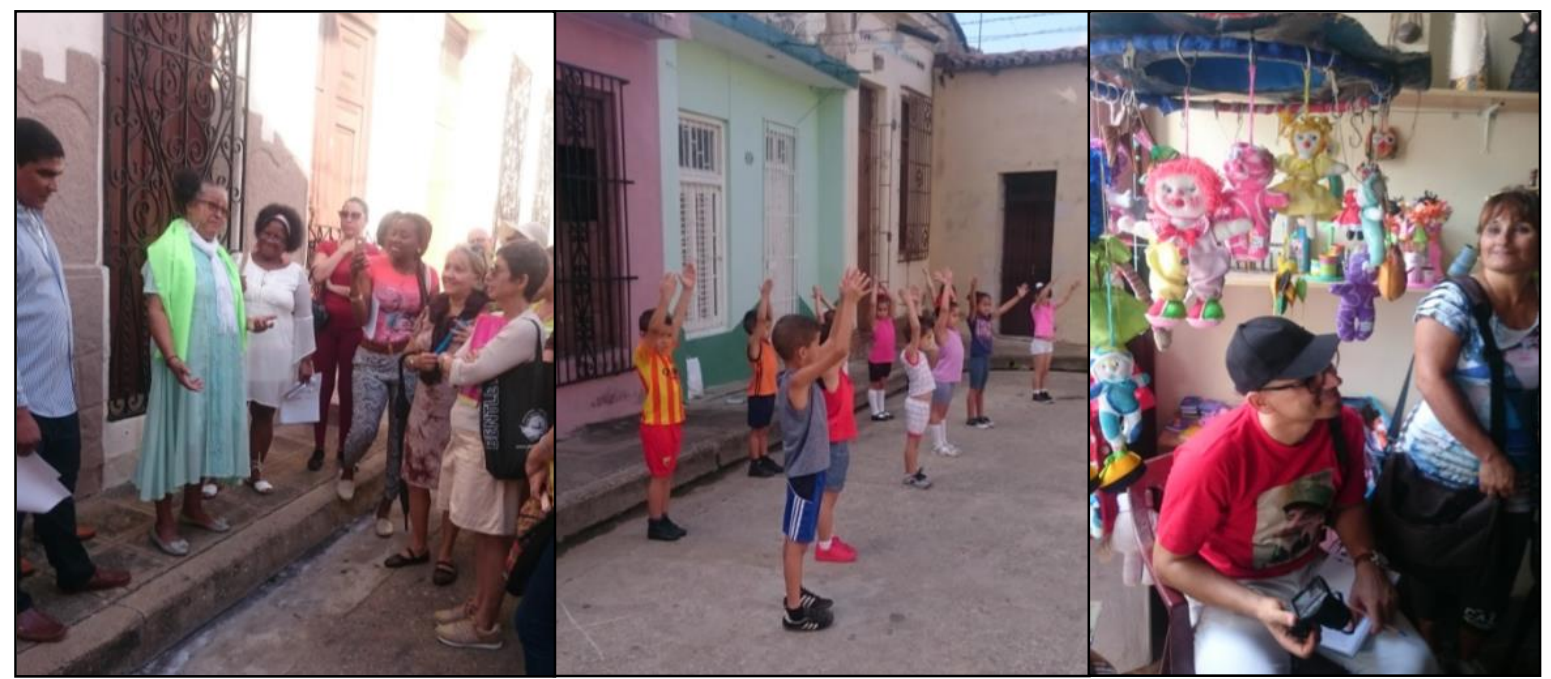

Fuente: Tomadas por la autora. Camagüey, Cuba. 2018

PatryTer| ISSN: 2595-0169 | vol. 2 | n. 4 | outubro 2019 | pp. 38-50 |Artigo 


\section{Conclusiones}

La historia de las ciudades es la historia del hombre, vinculada a un contexto geográfico, condicionado por factores económicos, políticos, sociales e ideológico culturales. La ciudad y su arquitectura forman parte de la cultura material y están sometidas a un uso dinámico y de tensión continua, donde muchas veces con el transcurso del tiempo deben ser capaces de asimilar los cambios que impone la sociedad en su continuo desarrollo. Estos cambios no deben significar agresiones a lamemoria colectiva de nuestras ciudades sino una incorporación de nuevos elementos de significación, acordes a los nuevos tiempos y que enriquezcan su identidad cultural. La identidad es una construcción social vinculada a los acontecimientos que ocurren en el seno de la propia comunidad, es en este sentido que se precisa buscar elementos de cohesión social en torno a sus valores y símbolos, asumidos y defendidos. La responsabilidad es de todos, si se quiere que la historia pueda seguir leyéndose en la piedra.

La ciudad de Santa María del Puerto del Príncipe, actualmente Camagüey, evidencia en su estructura física la permanencia de determinados símbolos y la incorporación de otros, como parte de esa cultura material que ha superado la prueba del tiempo y que refuerzan su identidad urbana. El reconocimiento de estos símbolos por la sociedad, unido a los usos tradicionales y nuevos, como resultado de prácticas contemporáneas de apropiación del espacio por los hombres son una muestra de la necesaria relación pasado-presentefuturo que señala un camino factible para la preservación patrimonial de nuestras ciudades.

\section{Referencias Bibliográficas}

ACC. Academia de Ciencias de Cuba. /s.a/. Caracterización de la provincia de Camagüey y diagnóstico de la desertificación y la sequía. / s.e/.

Almeida, M. (2015). La reconfiguración del paisaje urbano histórico como via para la preservación de la identidad cultural. Caso de estudio Camagüey. En Gómez, L. y Niglio, O., Conservación de centros históricos en Cuba. (Ed.) Volumen I. (pp. 247- 266). Roma: Editorial edA Esempidi Architettura, Aracne Editrice.

ANE. Archivo Nacional de España. Mapa del Puerto de Nuevitas 1796. Sección Ultramar. Sig. 60. Proc. Legajo 3896 bis, núm. 1. Extraído de Santa María del Puerto del Príncipe. Camagüey. Reimplantación de la Retícula. Camagüey. Gómez, L. (Inédito).
Barrios, L. (1881). Bosquejo geográfico militar de la Provincia de Puerto Príncipe, Barcelona, España.

Boisier, S. (1999). Teorías y Metáforas sobre desarrollo territorial. Santiago de Chile: Editorial de la ONU.

Bourdieu, P. (1993). La misere du monde, Seuil, Paris, 1993. Extraído de Revista Iberoamericana Astrágalo. Espacios, Migraciones, Alteridades De Haba, J. y Santamaría, E. "Sobre espacio, distancia y hospitalidad." No. 18, septiembre, 2001. pp. 15-31.

CEPAL (Comisión Económica para América Latina y el Caribe) (2012). Base de estadísticas e indicadores sociales (Badeinso). Panorama de la Población Mundial. Recuperado de http://estadisticas.cepal.org en julio de 2017.

Crespo, J. (2018). Cultura y modernidad en el cambio del paisaje histórico urbano de la ciudad de Camagüey. 1940-1950. En XII SimposioInternacional Desafíos en el Manejo y Gestión de Ciudades Camagüey, Cuba.

Colectivo de autores (1991). Manual para la reglamentación de los sectores urbanos antiguos. Instituto Colombiano de Cultura. Bogotá, Editorial Escala (primera edición).

Costa, E. (2018). Riesgos y potenciales de preservación patrimonial en América Latina y el Caribe. Investigaciones Geográficas. UNAM. http://dx.doi.org/10.14350/rig.59593

Chaos, M. T. (2005). Lenguaje de poderes en la estructura física de Santa María del Puerto del Príncipe. Siglos XVI-XVIII. (Tesis Doctoral). Universidad Pablo de Olavide, Sevilla, España. (inédita).

Chaos, M. T. (2011). La diversidad cultural y el respeto por la autenticidad de un sitio: Santa María del Puerto del Príncipe, actual Camagüey.Revista APUNTES. Vol. 24, No. 2, pp. 162-173. Bogotá, Colombia. ISSN 1657-9763,julio-diciembre 2011.

Chaos, M. T. (2015). La identidad cultural en el centro de la gestión turística de los núcleos monumentales. En Gómez, L. y Niglio, O., Conservación de centros bistóricos en Cuba.(Ed.) Volumen II. (pp. 657- 675). Roma: Editorial edA Esempidi Architettura, Aracne Editrice.

Chaos, M. T. y Marichal, A. M. (2015). La ciudad es mucho más que un lugar en el mapa. Arcada. Revista de Conservación del Patrimonio Cultural, XXX (1), pp. 46-53.

Chaos, M. T. (2018). Usos y apropiaciones del patrimonio urbano VS identidad perdida 0 conservada. PatryTer, (1), 1, pp. 22-33. DOI: https://doi.org/10.26512/patryter.v1i1.71 08 
Chaos, M. T.; Arnaiz, M.; Falls, D. y Sóñora, B. (2019). El patrimonio urbanoarquitectónico, un atractivo turístico de los destinos patrimoniales. Uniandes Episteme, 6(2), 291-305.

De la Cruz, J. (1844). Apuntes para la historia de la isla de Cuba correspondientes a la siempre fiel, muy noble y muy leal ciudad de Santa María del Puerto del Príncipe. Imprenta de Gobierno y Real Hacienda. La Habana, Cuba.

De Terán, F. (1989). La ciudad Hispanoamericana. El sueño de un orden. MOPU. Madrid, España.

De Santa Cruz, F. X. (1943). Historia de familias cubanas (6 t.). La Habana: Editorial Hércules.

Duany, A. y Plater, E. (2003). Práctica del postsuburbanismo. (Vol. 3). Colección Arquitectura y Ciudad. Ediciones Unión.La Habana, Cuba.

Espinosa, F. y Cortés, A. (2015). Confort higrotérmico en vivienda social y la percepción del habitante. Revista INVI, 30, (85), p. 227 42.

Falls, D.; Chaos, M. T.; Arnaiz, M.; y Peláez, R. (2019). La labor extensionista en la preservación del patrimonio del movimiento moderno desde las Cátedras Honoríficas. Uniandes Episteme, 6(2), pp. 232-245.

Fourquet, F. (1978). Los equipamientos del poder. Ciudades, territorios y equipamientos colectivos. Editorial Gustavo Gili, Barcelona, España.

García, A. (1990). Yo veía un pueblo grande. Editora Política La Habana, Cuba.

García, A. (2012). 30 maravillas del patrimonio arquitectónico cubano. Ediciones Polymita S.A. Ciudad de Guatemala.

George, P. (1969). Geografía urbana. Ediciones ARIEL, Barcelona, España.

Gómez, L. (1986). Conservación de Centros Históricos. (Tesis Doctoral). Instituto Superior Politécnico Jose Antonio Echevarria, La Habana, Cuba. (inédita).

González, R. A. (2016). Geografía urbana. Editorial Universitaria Félix Varela, La Habana, Cuba.

González, R. (2018). La Habana: dinámica socio espacial de las formas urbanas. PatryTer, (1), 1, pp. 1-12.

DOI: https://doi.org/10.26512/patryter.v1i1.7100

ICOMOS (2007). Foro sobre ciudades históricas y paisaje bistórico urbano. Grupo de trabajo de países iberoamericanos. [s.l] Recuperado 28 de enero del

2012

en http//www.todopatrimonio.com/pdf/cicop 2010/26_Actas_2010.pdf

Juárez, J. (1929). Apuntes de Camagüey. Imprenta El Porvenir, Camagüey, Cuba.
Luaces, J. A. (1946). Geografía de mi país. Camagüey. Editorial Echea, La Habana, Cuba. (primera edición).

Lefebvre, H. (1972). Espacio y Política. El derecho de la ciudad II. [s.1.]: Editorial Península.

Martí, J. (1988). Autores americanos aborígenes, Obras completas, Tomo. VIII.

Marichal, A.M. (2006). Patrón de desarrollo por sectores en el modelo de estructuración de ciudades intermedias. Camagüey como caso de estudio. (Tesis Doctoral). Instituto Superior Politécnico José Antonio Echeverría, La Habana, Cuba. (inédita).

Morales, F. (1999). Historia del descubrimiento de la conquista de América. Editorial Gredos, Madrid, España.

Morell, P. A. (1985). La Visita Eclesiástica. Editorial Ciencias Sociales, La Habana, Cuba. Extraído del Archivo General de Indias (AGI). Legajo Santo Domingo 2227. Carta del Obispo de Cuba (28 de junio de 1756).

Munford, L. (1966). La ciudad en la historia, Ediciones Infinito, Buenos Aires, Argentina.

Stevens, G. (1998). The Favoured circle: the social foundations of arquitecturaldistintions. Mits Press, Cambridge. Extraído de Revista Arqitextos. Facultad de Arquitectura y Urbanismo de la Universidad Ricardo Palma. Toca, A. "La fama en arquitectura. Favoreciendo a los favorecidos". No. 11. Editora Talleres Proyecto Arius SRL/2000. p. 93.

Pino, R. A. (2018). Modernización y deterioro del hábitat. Contradicciones y evidencias de la política urbana en la Ciudad de México.En Tercer Seminario Internacional Repensar la Metrópoli, Ciudad de México, México, octubre 2018.

Pogolotti, G. (2015,20 de diciembre). Las ciudades también son mortales. Periódico Juventud Rebelde, Cuba.

Racionero, L. (1986). Sistema de ciudades y ordenación del territorio. Alianza Editorial, Madrid. (Tercera edición revisada y ampliada).

Santos, M. (2007). O espaço do cidadão. São Paulo: Edusp.

Serrano F. M.; y Köster P. R. (2016). Una aproximación al turismo urbano. El valor de la ciudad empaquetada en el caso de Valencia. Revista de Economía, Sociedad, Turismo y Medio Ambiente: RESTMA, (2), 9-34.

Torres, J. (1888). Colección de datos históricos-geográficos y estadísticos del Puerto del Principe y su jurisdicción. Parte Primera. Noticias Preliminares. De los indios del Camagüey. Imprenta El Retiro, La Habana, Cuba.

\section{Fuentes documentales}


AHPC. Archivo Histórico Provincial de Camagüey. Fondo Personal Jorge Juárez Cano. Carpeta No. 5. Folio 5.

AHPC. Fondo Personal Juárez, J. Biografías. Caja No. 52. Expediente 159, pp. 48-50.

AHPC. Fondo Personal Juárez, J. Carpeta No. 3, p. 84.

AHPC. Fondo Personal Juárez, J. Legajo 5, p. 11.

AHPC. Fondo Personal Jorge Juárez Cano. Carpeta No. 15. 